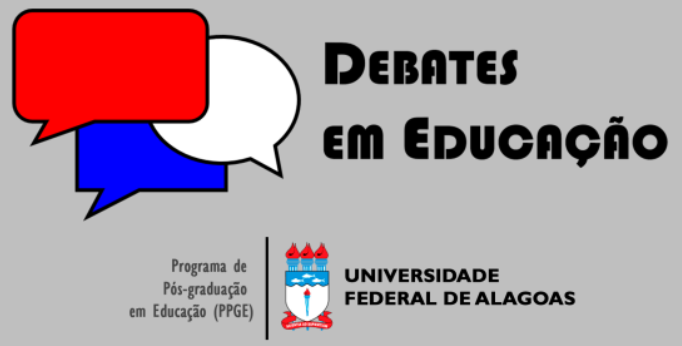

ISSN Eletrônico 2175-6600

Vol. 12 | Número Especial | 2020

Rosângela Oliveira Cruz Pimenta (5) iD

Universidade Federal de Alagoas (UFAL) rocpiment@yahoo.com.br

Sónia Valente Rodrigues

Universidade do Porto (UP) smcvro@gmail.com

\section{FORMAÇÃO CONTÍNUA DE PROFESSORES PORTUGUESES NO CONTEXTO DO ENSINO- APRENDIZAGEM DA EXPRESSÃO ESCRITA: ESTUDO PRELIMINAR}

\section{RESUMO}

Pretendemos divulgar os resultados de um estudo exploratório sobre o modo como se processa o ensino da escrita em sala de aula por professores com experiência recente de formação contínua nessa área. $\bigcirc$ estudo, realizado no primeiro trimestre de 2020 em escolas portuguesas do ensino público, tem natureza qualitativa, baseando-se na observação de aulas e na análise de material didático de dois professores de Português do $3 .^{\circ}$ ciclo do ensino básico e ensino secundário, tendo um deles frequentado, durante o ano letivo 2019/2020 uma ação de formação contínua sobre didática da escrita. $\bigcirc$ quadro conceptual inscreve-se na confluência de áreas como a investigação educacional, a formação de professores de Português e a didática da escrita. Embora limitados, os dados permitem sustentar questões de uma investigação futura mais ampla sobre práticas de ensino-aprendizagem da escrita e identificar dimensões que deverão ser reforçadas em tal prática. Permitem ainda reforçar a necessidade de formação contínua sistemática e regular em ensino da escrita como estratégia para potenciar o ensino da escrita na sala de aula.

Palavras-chave: Formação contínua de professores. Didática da escrita. Enfoque processual de ensino da escrita.

\section{CONTINUOUS TRAINING OF PORTUGUESE TEACHERS IN THE CONTEXT OF TEACHING- LEARNING OF WRITTEN EXPRESSION: PRELIMINARY STUDY}

\begin{abstract}
We intend to disseminate the results of an exploratory study on the way in which the teaching of writing in the classroom is carried out by teachers with recent experience of continuous education in this area. The study, carried out in the first quarter of 2020 in Portuguese public schools, has a qualitative nature, based on the observation of classes and the analysis of teaching material of two Portuguese teachers from the 3rd cycle of basic education and secondary education, one of them attended, during the school year 2019/2020, a continuous education on didactics of writing. The conceptual framework is part of the confluence of areas such as educational research, the education of Portuguese teachers, and the teaching of writing. Although limited, the data allow to raise questions of a broader future investigation on teaching-learning practices of writing and to identify dimensions that should be reinforced in such practice. They also make it possible to reinforce the need for systematic and regular continuous education in the teaching of writing as a strategy to enhance this activity in the classroom.
\end{abstract}

Keywords: Continuing teacher education. Didactics of writing. Procedural approach to teaching writing

Submetido em: 30/04/2020

Aceito em: 03/07/2020

Publicado em: 10/12/2020

do: http://dx.doi.org/10.28998/2175-6600.2020v I 2nEspp220-245 


\section{INTRODUÇÃO}

A oportunidade de analisar materiais didáticos desenvolvidos por professores e de observar a sua aplicação em sala de aula numa atividade de produção de textos, faz-nos perceber que os problemas com o ensino e a aprendizagem da escrita ainda são muitos e vários, fazendo deste tema uma área de estudo muito importante e atual.

Sabemos que as dificuldades enfrentadas pelos professores, inclusive em Portugal, ainda são muitas. Entre as razões apontadas pelos professores para essas dificuldades está, por exemplo, o número de alunos por turma, que obsta a um acompanhamento próximo do processo de escrita de cada aluno. Além disso, o número de turmas e de aulas por professores também é elevado, o que dificulta ainda mais este trabalho. Acresce a isto o facto de, apesar dos recentes esforços para um emagrecimento curricular, o programa oficialmente em vigor ainda ser extenso I e de os docentes responderem pela sua execução principalmente através dos exames finais de ciclo que os alunos realizam. Os manuais escolares (livros didáticos) usados nas aulas propõem um trabalho com a escrita, em grande parte, orientado para a compreensão do conteúdo estudado no domínio da educação literária2, mas sem abertura para uma produção textual voltada para os usos sociais da escrita, tão importante para a inserção do aluno-escritor/escrevente no mundo contemporâneo. Este problema, contudo, não constitui o cerne do nosso trabalho.

Apesar das dificuldades enunciadas, os professores ocupam-se do desenvolvimento da competência de escrita dos alunos. E muitos deles procuram formação específica em didática da escrita, com o propósito de aprofundarem os seus conhecimentos nesse domínio e de reverem as suas práticas, a partir da reflexão sobre elas. Seria, por isso, importante compreender melhor a repercussão que poderão ter na sala de aula as reflexões e o conhecimento produzidos na formação. Coloca-se, então, a questão: existem diferenças no modo como se processa o ensino-aprendizagem da expressão escrita por professores que frequentam formação e professores que não frequentam formação específica para o efeito? Se sim, em que residem essas diferenças?

Tendo em conta a natureza do objeto de pesquisa (os efeitos da formação no modo como o professor atua em aula centrada no ensino-aprendizagem da expressão escrita), optamos pela investigaçãoação como metodologia para este estudo exploratório. $\bigcirc$ nosso objetivo foi analisar como foram

\footnotetext{
' Em 2018, foram aprovadas as Aprendizagens Essenciais, documento curricular orientador do ensino-aprendizagem em Portugal, no âmbito do programa nacional de Autonomia e Flexibilidade Curricular, que «visa a promoção de melhores aprendizagens indutoras do desenvolvimento de competências de nível mais elevado, assumindo a centralidade das escolas, dos seus alunos e professores, e permitindo a gestão do currículo de forma flexível e contextualizada, reconhecendo que o exercício efetivo de autonomia em educação só é plenamente garantido se o objeto dessa autonomia for o currículo (DireçãoGeral da Educação). As Aprendizagens Essenciais foram elaboradas com base no Programa e Metas Curriculares de Português, currículo oficial em vigor desde 20 I 5 para o ensino básico e 2014 para o ensino secundário).

2 Embora a disciplina de Português integre cinco domínios de trabalho (da compreensão e expressão oral, leitura, escrita, educação literária e gramática), a educação literária é o domínio habitualmente em foco.
} 
desenvolvidas as aulas de produção textual de dois professores do ensino secundário em Portugal e discutir a adequação dos materiais didáticos por eles elaborados, tendo um dos profissionais participado de uma formação em didática da escrita e outro não. Para responder aos objetivos traçados, procedemos à observação de aulas, com vista à identificação dos gestos profissionais dos professores em momentos de ensino de produção escrita em aula, e à análise dos materiais citados. A partir das informações recolhidas, refletiremos sobre a influência da formação contínua nos materiais e nos gestos profissionais identificados.

Seguindo o modelo de investigação-ação proposto por Kemmis e McTaggart (1988), que propõem um conjunto de estratégias de ação específicas com uma natureza espiralar (identificação e análise do problema, planificação e implementação da ação, observação dos efeitos da ação, reflexão sobre esses efeitos, repetição do ciclo para melhorar a ação anterior), apresentaremos, em primeiro lugar, as preocupações especiais de professores que procuram formação sobre didática da escrita e o contexto em que essa formação se deu.

\section{CONTEXTO DA FORMAÇÃO}

Uma das necessidades permanentes na atividade docente é a da formação contínua. Não é possível dissociar a docência da constante atualização do conhecimento profissional em todas as áreas direta e/ou indiretamente relacionadas com o ensino e a aprendizagem. Esta necessidade está plasmada nos dispositivos legais que regulam a atividade dos docentes em Portugal. Os planos de formação e de desenvolvimento pessoal e profissional dos docentes são organizados por Centros de Formação de Associações de Escolas. Estas estruturas contam com diversos agentes colaborativos e instituições parceiras na promoção de ações de formação. De entre as parcerias estabelecidas, contam-se instituições de ensino superior, como os Institutos Politécnicos e as Universidades.

Em 20 16, a Faculdade de Letras da Universidade do Porto iniciou um programa de colaboração técnico-científica com 12 Centros de Formação de Associações de Escolas do norte do país, para formação contínua e desenvolvimento pessoal e profissional dos docentes. No âmbito dos protocolos firmados, foram desenhadas várias ações de formação em diferentes áreas da Didática do Português (língua materna), a partir das solicitações dos professores das escolas associadas aos referidos Centros de Formação.

Uma das áreas em que os professores solicitaram formação foi a da didática da escrita, fundamentada na necessidade de se ampliar o conhecimento de estratégias de ensino e de aprendizagem relacionadas com a competência de escrita dos alunos.

De modo a ser possível conhecer as necessidades específicas de formação num campo tão vasto quanto o da didática da escrita, foi organizada uma sessão de trabalho com os professores, para uma reflexão orientada pelas questões seguintes: (i) que aprendizagens consigo facilmente desencadear nos 
meus alunos? (ii) que aprendizagens são pedagogicamente mais desafiantes no meu trabalho como professor?

Em resposta à questão i), os professores reconheceram não sentir especial dificuldade quando promovem em aula aprendizagens que levam os alunos a serem capazes de3:

a) utilizar uma caligrafia legível (indicador relacionado com a capacidade de redigir textos com coerência e correção linguística);

b) respeitar o tema (indicador relacionado com a capacidade de redigir textos com coerência e correção linguística);

c) respeitar a tipologia textual (indicador relacionado com a capacidade de redigir textos com coerência e correção linguística);

d) organizar o texto em parágrafos;

e) responder por escrito, de forma completa, a questões sobre um texto (indicador relacionado com a capacidade de escrever para expressar conhecimentos);

f) escrever textos narrativos, textos biográficos, comentário, retrato e autorretrato, diário, cartas dirigidas a diferentes destinatários e com diferentes finalidades, guiões de entrevista (indicadores relacionados com a capacidade de escrever textos diversos);

g) escrever, por iniciativa e gosto pessoal, textos diversos (indicador relacionado com a capacidade de ler e escrever para fruição estética);

h) editar os textos escritos, em diferentes suportes, após revisão.

As respostas à questão ii) identificaram como principal desafio pedagógico-didático levar o aluno a:

i) utilizar, com progressiva autonomia, estratégias de planificação como pesquisar informação pertinente e elaborar planos (definir tópicos e organizá-los);

j) ordenar e hierarquizar a informação, tendo em vista a continuidade de sentido, a progressão temática e a coerência global do texto (descritor de desempenho relacionado com a capacidade de redigir textos com coerência e com correção linguística);

k) escrever textos com a tomada de uma posição, apresentação de razões que a justifiquem e uma conclusão coerente (descritor de desempenho relacionado com a capacidade de escrever textos argumentativos);

I) avaliar a correção e a adequação do texto escrito;

o) reformular o texto escrito, suprimindo, mudando de sítio e reescrevendo o que estiver incorreto/desadequado.

\footnotetext{
${ }^{3}$ Os objetivos de aprendizagem e descritores de desempenho aqui considerados são extraídos de um dos documentos orientadores do ensino de Português: Programa e Metas Curriculares de Português.
} 
mais desafiante para os professores parece residir em ações estratégicas de ensino que promovam nos alunos aprendizagens como o recurso a estratégias (como planificar, rever, aperfeiçoar), quando escrevem, e atitudes propícias à constante resolução de problemas inerentes ao processo de escrita. As informações recolhidas sugeriam, portanto, haver necessidade de centrar a formação no enfoque processual do ensino da expressão escrita.

Um plano de formação e desenvolvimento profissional de professores centrado no enfoque processual do ensino da expressão escrita responderá às necessidades de aprofundamento do conhecimento profissional expressas pelos docentes. Para a construção desse plano foi crucial o referencial teórico oriundo das diversas áreas científicas que têm por objeto de estudo a escrita em diferentes perspectivas (cognitiva, psicolinguística, didática, textual, sociolinguística, pragmática, entre outras). A investigação fecunda em torno do ensino da escrita das últimas décadas traz contributos produtivos para o trabalho do professor em sala de aula. Para o desenho da ação de formação dirigida aos professores, socorremo-nos de alguns desses contributos em que se apoia a fundamentação teórica, que passamos a apresentar.

\section{FUNDAMENTAÇÃO TEÓRICA}

$\mathrm{Na}$ reflexão conjunta dos professores em torno do ensino da expressão escrita, durante a formação, um dos desafios didáticos mencionados de modo mais expressivo dizia respeito à morosidade na aprendizagem de estratégias inerentes ao processo de escrever por parte dos alunos. Embora o ensino da expressão escrita contemple diversos enfoques (CASSANY, 1990), nem todos têm uma presença tão relevante nos documentos oficiais. No documento de orientação curricular atualmente em vigor para o ensino da língua materna em Portugal (PORTUGAL, 2018), estratégias como "pesquisar informação pertinente", "recolher informação", "definir tópicos", "organizar os tópicos num plano de texto", "hierarquizar informação", "avaliar a correção e a adequação do texto", "corrigir", "rever" e "reformular o texto escrito" constituem aprendizagens essenciais da competência de escrita em todos os anos da escolaridade obrigatória (dos 6 aos 18 anos de idade). Compreende-se, por isso, que os professores tenham necessidade de aprofundar conhecimento pedagógico-didático nesta área: como se organiza uma aula orientada para estas aprendizagens? Que atividades se propõem aos alunos? Como se avaliam as aprendizagens realizadas pelos alunos relativamente às estratégias do processo de escrita? Foram algumas das questões suscitadas por eles no momento dos encontros.

Num ensino da expressão escrita orientado por um enfoque processual, o centro é o aluno como "aquele que escreve", como explica Cassany (1990, p. 73): 
Este enfoque pretende enseñar al alumno a pensar, a hacer esquemas, a ordenar las ideas, a pulir la estructura de la frase, a revisar el escrito, etc. Lo importante es que al final del curso el alumno sea capaz de hacer eso, y no tanto que los textos que escriba no contengan incorrecciones.

A ação estratégica de ensino do professor é motivada pelas aprendizagens que se pretende que o aluno realize. No caso do enfoque processual do ensino da expressão escrita, as aprendizagens desejadas são estratégias e atitudes associadas4 ao processo de escrita. Tendo por base as investigações que a psicologia cognitiva e a didática têm produzido ao longo dos anos sobre o processo de escrita, podem ser mencionadas aprendizagens como:

-estratégias - fazer um plano de trabalho, gerar ideias (apoiando-se em diversas técnicas como ler, ver documentários, pesquisar na Internet, conversar com outros, entrevistar especialistas, entre outras), organizar as ideias (tendo em mente o leitor e o contexto comunicativo), avaliar o texto (tendo em mente o objetivo comunicativo e a adequação), aperfeiçoar o texto, corrigir os erros;

-atitudes5 - iniciativa na pesquisa de informação, método na organização dos dados pesquisados, planeamento do trabalho, paciência na revisão do esboço, antecipação da reação do leitor ao texto, persistência no aperfeiçoamento, receptividade para apreciações críticas ao texto, autonomia no emprego de diferentes estratégias.

Sabemos da existência de diversos modelos didáticos para a estruturação de sequências de aprendizagem da expressão escrita. Embora baseados em diferentes quadros teóricos, estes modelos têm em comum, entre outros aspetos, a integração dos contributos da investigação da psicologia cognitiva sobre o processo da escrita. Não sendo nosso objetivo apresentá-los aqui, nem fazer uma comparação entre eles, referem-se, a título de exemplo, os seguintes: $O$ Estaleiro (chantier), de J. Jolibert e do Grupo de Pesquisa de Ecouen (JOLIBERT, I988; JOLIBERT e SRAÏKI, 2006); o Modelo de Estratégia de EnsinoAprendizagem da Escrita (SANTOS, 1994); as Sequências Didáticas para Aprender a Escrever, implementadas pelo grupo GREAL, de Barcelona (CAMPS, 2003); a Sequência Didática, na perspetiva do Interacionismo Sociodiscursivo (DOLZ, NOVERRAZ e SCHNEUWLY, 2004); a Sequência de Ensino como dispositivo para a aprendizagem da escrita (PEREIRA, ALEIXO, CARDOSO e GRAÇA, 20I0; PEREIRA, CARDOSO e GRAÇA, 2013) e o Percurso Didático (JORGE, 2019) Todos estas propostas contemplam espaço para aulas em que se trabalha a planificação, a textualização e a revisão. Estas aulas centradas no processo de escrita do aluno podem assumir diversas configurações, mais ou menos estruturadas, como afirma Cassany (1990, p. 74):

\footnotetext{
${ }^{4}$ Tomamos como referência para o conceito de 'atitudes' a definição seguinte: "Disposição ou tendência aprendida para avaliar coisas ou reagir a ideias, pessoas ou situações de determinadas formas, seja consciente ou inconscientemente. Atitudes estão sustentadas por valores e crenças e influenciam o comportamento." (UNESCO-IBE, 2016).

${ }^{5}$ Sobre as atitudes necessárias para vencer dificuldades próprias do ato de escrita (bloqueios, receio de que se possa vir a escrever mal ou receio da página em branco, resistências várias nas diferentes etapas do processo), ver Pinto (2014, pp. $194-$ 196).
} 
De echo, la clase puede adoptar diversas formas. Se puede trabajar de una manera más programada, con tareas e instrucciones precisas sobre que se tiene que hacer, colaborando en grupo, poniendo en común los resultados, etc.; o puede fluir espontaneamente según el ritmo y los intereses de cada alumno, sin ejercicios ni organización concretos, sólo con una tarea general muy abierta. Por ejemplo, dado un tema determinado, el profesor puede dar instrucciones detalladas cada diez o quince minutos sobre lo que se tiene que hacer para desarrollar el tema escrito [...]. Por outra parte, el tiempo de clase se puede convertir también en un espácio libre y autónomo para que cada uno escriba a su ritmo unos textos determinados [...]. En este caso, el profesor se convierte en un supervisor-colaborador del alumno [...]

Os autores acima referidos, a par de outros cuja investigação didática traz também contributos relevantes (AMOR, 1993; CAMPS, 1990, 1994; ANTUNES, 2003; CASSANY 1989, 1990, 1995), destacam como produtivas no ensino-aprendizagem da expressão escrita atividades que podem ser organizadas em três módulos, relacionados com as três estratégias de escrita que os modelos explicativos referem (pré-escrita ou planificação, escrita ou textualização, pós-escrita ou revisão), embora cientes de que esta divisão se justifica apenas por comodidade expositiva.

Em fase de pré-escrita, importa que os alunos sejam levados a:

i.reconhecer as variáveis da situação de comunicação que determinam o género de texto a escrever (destinatário, objetivo comunicativo, género de texto);

ii.conhecer, através da leitura e/ou da audição, textos do género textual requerido na situação de comunicação a considerar;

iii. evocar conhecimento e/ou adquirir informação nova sobre o domínio de referência que será considerado no texto a escrever;

iv.selecionar e hierarquizar informação mobilizada e/ou adquirida, tendo em conta a situação comunicativa de base e os objetivos comunicativos traçados.

Para a construção de uma representação do domínio de referência, são múltiplas as atividades que os alunos podem realizar. Podem incluir leitura, pesquisa através de consulta (com tomada de notas, fichas de leitura, por exemplo), visionamento (de filmes, de documentários, de fotografias, por exemplo), interação oral (como entrevistas, consultas orais, diálogos, debates, por exemplo).

O desenvolvimento da consciência e do conhecimento explícito das variáveis comunicativas pode ser promovido por um questionário pedagógico conduzido para respostas relacionadas com "i) a identidade do destinatário a quem se vai escrever (estatuto social e papel psicológico); ii) o objeto comunicativo que se tem em vista no ato de escrita em questão; iii) o modo de veicular o conteúdo referencial já selecionado [... . ; iv) o "onde" e o "quando" da enunciação" (SANTOS, 1994, p. 140).

Da análise da situação comunicativa decorrem todas as atividades relacionadas com gêneros de texto, planos de texto e sequências textuais, sobretudo as que se ligam estreitamente à situação de comunicação e ao(s) objetivo(s) comunicativo(s) que determinam o texto que o aluno vai escrever. De entre as atividades possíveis estão, por exemplo, ler textos de diferentes gêneros sobre o mesmo tópico, escrever sobre o mesmo tópico textos de gêneros diferentes (por exemplo, com vista à sensibilização para 
os perigos da destruição do ambiente, escrever sobre o mesmo tópico um discurso apelativo para intervenção pública e um poema para ser cantado), conforme sugerido por Santos (1994). Esta autora sublinha a importância deste tipo de atividades que proporciona "o desenvolvimento da competência sociopragmalinguística dos aprendentes, pela variedade de registos e funções da linguagem que eles se veem obrigados a aplicar às mais diversificadas situações de comunicação" (SANTOS, I994, p. I4I).

Na fase de escrita, são cruciais as atividades de estruturação/planificação, que partem de um trabalho de desenvolvimento da consciência e do conhecimento explícito do aluno sobre as regularidades que ocorrem ao nível do plano de texto. Como referem Jorge e Coutinho (2017, p. 78):

\footnotetext{
Dá-se o nome de plano de texto a esta estruturação, que permite construir a organização global de um texto (do ponto de vista da produção) e reconstruí-la (do ponto de vista da interpretação e análise).

plano de texto é uma macroestrutura textual simultaneamente semântica e estrutural, na medida em que resulta da articulação de duas vertentes - a da forma e a do sentido.
}

As autoras, citando Adam (2008), anotam como mecanismos linguísticos associados à organização estrutural do texto: a mudança de parte, de capítulo, ou de parágrafo; títulos, subtítulos; organizadores textuais; pontuação; estrofação e versificação (na poesia); paginação em geral; tipografia; indicações numéricas; marcação de alíneas; presença de componentes icónicas (fotografia, desenho, infografia). Quanto à vertente semântica da estruturação, referem que "os blocos que constituem o texto possuem unidade temática", que "pode ser evidenciada através de paráfrases e de resumos - estes últimos frequentemente explicitados no título e em intertítulos" (COUTINHO, 201। apud JORGE e COUTINHO, 2017, p. 78).

As atividades de textualização são, muitas vezes, realizadas pelos alunos individualmente, em aula ou em casa. Contudo, cientes de que o professor sabe adequar a melhor estratégia aos seus alunos e ao contexto de aprendizagem (tendo em conta, por exemplo, o tempo disponível), não podemos deixar de destacar a importância de realizar em sala de aula as atividades de textualização.

Marcuschi (2010, p. 9) lembra-nos que "falar ou escrever bem não é ser capaz de adequar-se às regras da língua, mas é usar adequadamente a língua para produzir um efeito de sentido numa dada situação" e isto deve ser considerado em todas as atividades da língua, como nas atividades de retextualização: na passagem de um texto escrito para outro texto escrito (a pesquisa sobre um tema em texto expositivo, por exemplo) ou de um texto falado para um texto escrito (transformar o que se disse sobre as impressões de um filme em texto verbal escrito).

As atividades de textualização abrem, assim, inúmeras possibilidades para um trabalho pedagógicodidático relacionado com o conjunto das propriedades ligadas à textualidade, isto é, aquelas propriedades "que uma manifestação da linguagem humana deve possuir para ser reconhecida como texto" (MATEUS 
et al., 2003, p. 87)6. Uma das atividades que apresenta vantagens pedagógico-didáticas nesta fase da textualização é a interação oral para negociação coletiva, com registo escrito subsequente no quadro, após seleção consensual das unidades linguísticas mais apropriadas, como refere Santos ( 1994):

O professor tem assim a possibilidade de contrariar a tendência natural dos aprendentes mais jovens [...] para a aplicação de estratégias de estruturação centradas em fenómenos de nível frásico. Pode eventualmente levá-los a transcender essas operações locais, circunscritas a aspetos isolados do sistema, de tipo lexical ou morfossintático, preferencialmente $[\ldots]$

Por outro lado, o trabalho coletivo - enquanto actividade de interaç̧ão oral - permite o "pensar em voz alta", o qual faculta: i) a intervenção reguladora do professor, no sentido de reorientar as propostas e/ou hipóteses dos aprendentes, com explicitação do porquê desses reajustamentos, em ordem à aprendizagem de estratégias de auto-regulação; ii) a observação, negociação e aplicação de unidades linguísticas em função de uma prática que se vai cumprindo em simultâneo com a reflexão sobre essa mesma prática (SANTOS, 1994, pp. 146-147).

As atividades de revisão não estão necessariamente localizadas apenas como etapa final do processo de escrita do texto, dado que o processo de escrita é recursivo (FLOWER e HAYES, I98I). Como refere Pinto (20।4), a revisão constitui um processo de pensamento que pode emergir quando o escritor/escrevente decide avaliar ou rever o seu texto ou os seus planos; à medida que vai escrevendo o texto, o escritor/escrevente "não só escreve, mas também lê, descobre, censura, critica e edita. As suas ideias estão assim a ser definidas, selecionadas, rejeitadas, avaliadas e organizadas em permanência [...]” (PINTO, 20I4, p. 200).

Os estudos e as investigações recentes têm contribuído com propostas pedagógico-didáticas quase inesgotáveis para levar os alunos a desenvolverem a capacidade de revisão de texto como estratégia no processo de escrita. Serafini ( 1989) demonstra que os professores tendem a corrigir os textos dos alunos de três maneiras, que são imprescindíveis para entendermos o processo de revisão e reescrita, a partir da interpretação que o professor faz do texto do aluno. São três os tipos de corretores apontados pela autora:

I.corretivo - quando o professor corrige apenas indicando/apontando nas margens ou no corpo do texto os problemas encontrados;

2.resolutivo - quando o professor corrige "consertando" todos os problemas encontrados no texto, ou seja, ele resolve pelo aluno a dificuldade apresentada;

3.classificatório - quando o professor cria códigos, sinais ou símbolos que se referem ao erro que o aluno cometeu.

A esta proposta, Ruiz (2005), num estudo importante sobre os gestos didáticos dos professores, acrescenta um quarto tipo de correção:

\footnotetext{
${ }^{6} \mathrm{Na}$ proposta de Beaugrande e Dressler (1981), são sete essas propriedades: intencionalidade, aceitabilidade, informatividade, situacionalidade, intertextualidade, coerência e coesão. Interessa conhecer as propostas didáticas que Lopes e Carapinha (2013) apresentam, a partir do conceito de textualidade e das propriedades referidas, para uma aprendizagem com incidência na coesão e coerência textuais.
} 
4.textual-interativo - quando o professor recorre à escrita de bilhetes, nos quais faz comentários (sobre os aspetos positivos e sobre os problemas encontrados), apresentando sugestões para a reescrita do texto.

Neste trabalho, Ruiz (2005) analisa o movimento do professor ao entrar no texto do aluno (com a tipologia das correções) e o turno do aluno quando recebe o texto corrigido e é desafiado a reescrever. Com a análise, torna evidente que, quando a correção do professor não faz sentido para o aluno, a reescrita não ocorre ou ocorre de maneira inadequada. Por isso, o professor, enquanto revisor textual, tem uma enorme responsabilidade relativamente à qualidade das textualizações dos alunos.

Fuzer (2012) amplia e aprofunda os estudos sobre os bilhetes orientadores e propõe também, como Ruiz (2005), um roteiro para a elaboração do bilhete orientador no qual: a) prevê as reações do leitor ao texto com frases do tipo "Adorei seu texto!"; b) elogios à produção (p. ex. "Seu texto melhorou muito!); c) orientações para a reescrita ("Adorei seu texto. Porém, sugiro a você alguns ajustes, para tornamos seu texto ainda melhor) e d) incentivo à reescrita ("Feitos esses ajustes, G, seu texto ficará ainda melhor. Aguardo para reler seu conto e ver como ficou. Boa reescrita! Abraços, profa Nome).

Muitos dos contributos gerados pela investigação em didática da escrita, aqui apenas anotados, são conhecidos dos professores, uma vez que estão integrados nos planos de formação inicial, que concede habilitação profissional para a docência na área do Português língua materna. Sabemos, contudo, com Tardif (20 I0), que são diversas as fontes que participam do processo de tornar-se professor ao longo de uma vida: saberes provenientes da vida familiar, da escola em que o professor estudou, da sua cultura pessoal, da formação acadêmica inicial e contínua e aqueles oriundos da própria prática docente. $\bigcirc$ autor refere que as experiências familiares e da escolaridade básica são muito persistentes e sobrepõem-se à formação universitária, que não é capaz de as transformar. A vivência escolar básica, pela dimensão da sua imersão, deixa marcas profundas nas representações acerca do ofício de ser professor e ser aluno. Isso deve-se, sem dúvida, ao facto de a identidade profissional do professor ser parte da sua identidade pessoal pois "o professor é a pessoa, e uma parte importante da pessoa é o professor" (NIAS, I991, apud NÓVOA, 1992). Acresce, então, toda a experiência profissional acumulada à sua prática letiva.

Dito isto, conceber um plano de formação para professores com largos anos de experiência e de conhecimento profissional não pode ser encarado como um programa construído "de fora" (a universidade) "para dentro" (a escola). A formação contínua, como defende NÓVOA (20|7, p. |4), "desenvolve-se no espaço da profissão, resulta de uma reflexão partilhada entre os professores, com o objetivo de compreender e de melhorar o trabalho docente". Nesse sentido, a experiência concreta de ser professor como objeto de reflexão, de discussão e de reestruturação pelo próprio professor constitui o cerne da formação. Com base neste quadro de referência, foi construído o plano da ação de formação que a seguir apresentamos. 


\section{PLANO DE AÇÃo}

O desenho do plano de ação, no projeto de investigação-ação realizado, foi traçado com base em dois pressupostos, enunciados como teses por Nóvoa (2002). O primeiro pressuposto consiste em conceber uma ação de formação contínua em que são valorizadas "as atividades de (auto)formação participada e de formação mútua, estimulando a emergência de uma nova cultura profissional no seio do professorado" (NÓVOA, 2002, p. 63). O segundo pressuposto assenta na tese de que "a formação contínua deve alicerçar-se numa 'reflexão na prática e sobre a prática', através de dinâmicas de investigação-ação e de investigação-formação, valorizando os saberes de que os professores são formadores" (NÓVOA, 2002, p. 64). De acordo com este autor, é necessário diversificar os modelos e as práticas da formação contínua, construindo dinâmicas que promovam a relação dos professores com o saber a partir da reflexão sobre as suas práticas pedagógicas, questionando as crenças e representações cristalizadas. Como afirma Nóvoa (2002, p. 64), "a formação passa pela experimentação, pela inovação, pelo ensaio de novos modos de trabalho pedagógico. E por uma reflexão crítica sobre a sua utilização".

Por compreendermos a formação contínua como lugar privilegiado de reflexão sobre a prática docente e uma possibilidade de aprofundamento de conhecimentos a partir da prática pedagógica quotidiana, é que entendemos a sua relevância para qualificar o trabalho com o ensino de escrita na sala de aula. Por essa razão, optou-se pela modalidade "oficina de formação", orientada para "a concepção, a construção e a operacionalização quer de metodologias e técnicas, quer de instrumentos, recursos e produtos pedagógicos e/ou didáticos com vista a resolver problemas concretos e devidamente identificados ao nível da escola e/ou da sala de aula" (CCPFC, Regulamento para Acreditação e Creditação de Ações de Formação Contínua, secção I, ponto 2).

A oficina teve por finalidade a construção colaborativa e a implementação de percursos didáticos orientados por um enfoque processual do ensino da expressão escrita, seguidas de uma partilha de experiências letivas geradora de reflexão. A duração total da oficina de formação era de 30 horas, divididas em sessões presenciais (num total de 15 horas) e em trabalho autónomo (num total de 15 horas). As sessões presenciais, com a duração de 2 horas (duas das sessões com duas horas e trinta minutos), foram realizadas durante o período letivo em horário pós-laboral, organizadas em quatro etapas, de acordo com a representação do esquema seguinte. 


\begin{tabular}{|c|c|c|c|c|c|c|}
\hline Etapa I & Etar & & & a 3 & & \\
\hline $\begin{array}{c}\text { Sessão | } \\
2019.10 .08 \\
17 \mathrm{~h}|5-19 \mathrm{~h}| 5\end{array}$ & $\begin{array}{c}\text { Sessão } 2 \\
2019.1 \mid .19 \\
|7 h| 5-19 h \mid 5\end{array}$ & $\begin{array}{c}\text { Sessão } 3 \\
2019.12 .17 \\
|7 \mathrm{~h}| 5-9 \mathrm{~h} \mid 5\end{array}$ & $\begin{array}{c}\text { Sessão } 4 \\
2020.01 .28 \\
\text { |7h | 5- | 9h | } 5\end{array}$ & $\begin{array}{c}\text { Sessão } 5 \\
2020.01 .28 \\
\text { |7h|5-19h| } 5\end{array}$ & $\begin{array}{c}\text { Sessão } 6 \\
\text { 2020.02. | | } \\
\text { |7h | 5- | 9h45 }\end{array}$ & $\begin{array}{c}\text { Sessão } 7 \\
2020.03 .03 \\
\text { | 7h | 5- 19h45 }\end{array}$ \\
\hline $\begin{array}{l}\text { Contextualiza- } \\
\text { ção do trabalho } \\
\text { a realizar. } \\
\text { Debate em } \\
\text { torno dos } \\
\text { desafios } \\
\text { pedagógicos } \\
\text { didáticos no } \\
\text { ensino da } \\
\text { escrita. }\end{array}$ & $\begin{array}{l}\text { Apresenta- } \\
\text { ção dos } \\
\text { resultados do } \\
\text { debate da } \\
\text { sessão } \\
\text { anterior. } \\
\text { Fundamen- } \\
\text { tos do } \\
\text { enfoque } \\
\text { processual do } \\
\text { ensino da } \\
\text { escrita. }\end{array}$ & $\begin{array}{l}\text { Análise de } \\
\text { estratégias } \\
\text { (enfoque } \\
\text { processual do } \\
\text { ensino da } \\
\text { escrita). } \\
\text { Variáveis } \\
\text { específicas da } \\
\text { organização } \\
\text { do contexto } \\
\text { e processo } \\
\text { de ensino- } \\
\text { aprendiza- } \\
\text { gem. }\end{array}$ & $\begin{array}{l}\text { Construção } \\
\text { colaborativa } \\
\text { de percursos } \\
\text { didáticos para } \\
\text { implementa- } \\
\text { ção das aulas. }\end{array}$ & $\begin{array}{l}\text { Construção } \\
\text { colaborativa } \\
\text { de percursos } \\
\text { didáticos para } \\
\text { implementa- } \\
\text { ção das aulas. }\end{array}$ & $\begin{array}{l}\text { Relato das } \\
\text { experiências } \\
\text { letivas de } \\
\text { implementa- } \\
\text { ção. Reflexão } \\
\text { sobre } \\
\text { estratégias de } \\
\text { ensino para a } \\
\text { fase de revisão } \\
\text { do texto. }\end{array}$ & $\begin{array}{l}\text { Relato das } \\
\text { experiências } \\
\text { letivas de } \\
\text { implementa- } \\
\text { ção dos planos } \\
\text { de aula } \\
\text { produzidos. }\end{array}$ \\
\hline
\end{tabular}

Fonte: As autoras

Esta organização da formação e o intervalo entre os encontros permitiu que o professor entrasse em contacto com autores que fundamentam o ensino de escrita; refletisse sobre a sua prática; elaborasse materiais didáticos para serem aplicados em sala de aula e tivesse a oportunidade de relatar como se deu o desenvolvimento das aulas, a partir do material elaborado.

Para melhor se compreender o processo de obtenção de dados na investigação realizada, apresentamos a seguir os aspetos metodológicos que deram forma a este estudo.

\section{DESENHO METODOLÓGICO DO ESTUDO REALIZADO}

O estudo exploratório realizado é, como foi referido, de natureza qualitativa, com caráter descritivo. Para a recolha de dados foi utilizada a técnica da observação de situações pedagógicas, que, nas palavras de Estrela (1990, p. | 28), constitui o fundamento de toda a ação educativa:

Só a observação permite caracterizar a situação educativa à qual o professor terá de fazer face em cada momento. A identificação das principais variáveis em jogo e a análise das suas interacções permitirão a escolha das estratégias adequadas à prossecução dos objetivos visados. Só a observação dos processos desencadeados e dos produtos que eles originam poderá confirmar ou infirmar o bem fundado da estratégia escolhida.

A observação de aulas foi realizada por uma das autoras deste artigo, que analisou alguns aspetos essenciais do processo pedagógico em foco, procedendo ao levantamento de indicadores que permitem uma caracterização das situações observadas. A necessidade de recorrer a uma observadora exterior à situação educativa observada justifica-se pelo facto de existirem dificuldades e limitações quando o professor é também o observador, como observa Estrela (1990, p. 128), quando refere que ao ser 
simultaneamente actor e observador, a atenção do professor é solicitada e repartida por grande número de tarefas e de indivíduos, tornando ainda mais difícil uma observação objectiva e sistemática. Assim, há aspetos da situação que fogem ao controlo do professor, o que, por vezes, impede uma avaliação dos factores em jogo.

A cada uma das observações realizadas correspondeu o registo de notas de campo, isto é, "o relato escrito daquilo que o investigador ouve, vê, experiencia e pensa no decurso da recolha e refletindo sobre os dados de um estudo qualitativo" (BOGDAN \& BIKLEN, 1994, p. I50).

Para este estudo exploratório, foi selecionado aleatoriamente um dos professores que frequentou a ação de formação sobre didática da escrita, já referida. A fim de ser possível compreender melhor a influência da formação neste professor, foi convidado a participar no estudo um outro professor, que também lecionava Português ao $10^{\circ}$ ano, mas não frequentou a formação. Os dois professores participantes do estudo tinham idades compreendidas entre os 30 e os 50 anos, ambos com licenciatura em Letras. O professor que não participou na formação de didática da escrita será nomeado PI, o professor que participou nessa formação será P2. As aulas observadas a PI e a P2 pertenciam a uma sequência de aprendizagem mais ampla relacionada com a obra Farsa de Inês Pereira, de Gil Vicente.

As escolas às quais pertenciam os professores envolvidos têm também perfis diversos. Uma delas é bem avaliada no Exame Nacional e integra, na sua oferta educativa, o $3 .^{\circ}$ ciclo do ensino básico $\left(7 . .^{\circ}, 8 .^{\circ}\right.$ e 9. anos), o ensino secundário (cursos científico-humanísticos e os cursos profissionais de Técnico de Gestão de Sistemas Informáticos, de Técnico Comercial e de Técnico de Turismo) e qualificação para adultos. Situa-se numa freguesia de elevado padrão aquisitivo, na cidade do Porto, e pode ser considerada uma escola de classe média alta.

A outra é a sede de um agrupamento de escolas que contém seis escolas de educação básica, incluindo a própria, e seis jardins-de-infância. Na escola sede, campo de nossa investigação, existe a oferta de educação pré-escolar, de ensino básico, de ensino secundário (os cursos científico-humanísticos nas áreas de Ciências e Tecnologias, de Ciências Socioeconómicas e de Línguas e Humanidades) e cursos profissionais (de Técnico de Gestão e Programação de Sistemas Informáticos, de Técnico de Frio e Climatização, de Técnico de Eletrônica, Automação e Computadores e de Técnico em Animação de Turismo). Situa-se nos arredores do Porto, próxima a muitas outras escolas e pode ser considerada uma escola de classe média.

Ambas contam com portaria, recepção, sala de professores, laboratórios, biblioteca, cantina, espaços de convívio, sala de reuniões, todos os ambientes em boas condições. A primeira escola conta com um padrão arquitetônico mais luxuoso.

De acordo com os documentos curriculares oficiais (Aprendizagens Essenciais e Programas e Metas Curriculares do ensino de Português), a disciplina de Português no ensino secundário deve envolver, entre 
outros domínios, o ensino de produção de textos, o qual contempla, em todos os anos, as ações de planificar, escrever, rever e reescrever.

Segundo os professores envolvidos, nas turmas observadas, as aulas de produção textual ocorrem com regularidade, mas não com frequência, por isso foi necessário agendar previamente com os professores as aulas de Português em que haveria propostas de atividades de escrita.

A turma de PI frequentava o curso científico-humanístico de Artes e a do P2 o curso profissional de Técnico de Gestão e Programação de Sistemas Informáticos. $\bigcirc$ total de alunos em cada turma oscilava entre 25 e 30 alunos, numa faixa etária entre os 15 e os 17 anos. Ambos os cursos funcionavam em regime diurno, na região metropolitana do Porto. Todas as salas tinham mesas duplas, quadro branco, projetor, uma mesa e um computador exclusivo para o professor, com uma caixa próxima para os alunos deixarem os seus telemóveis durante a aula.

O processo para os professores conduzirem o ensino-aprendizagem a partir do material elaborado, em forma de fichas de trabalho, foi de quatro tempos letivos na Turma I (TI) e de três tempos letivos na Turma 2 (T2). As observações ocorreram nos meses de janeiro e fevereiro de 2020. Foram observadas sete aulas, com duração de 50 minutos cada, todas registadas no diário de campo. Na TI, foram observadas três aulas de 50 minutos e um bloco letivo de Ih40; na T2, as observações foram realizadas em três blocos letivos, portanto, com uma duração de I h40 cada. Foram utilizadas as notas de campo como instrumento de recolha de dados.

O corpus aqui analisado é constituído pelo material elaborado pelos professores e pelas notas de campo das aulas nas quais estas fichas foram aplicadas.

Relativamente ao material dos professores, procedeu-se a uma análise de conteúdo, tendo em conta as seguintes categorias e subcategorias:

A.a relação das propostas de produção de texto com o conteúdo estudado (A Farsa de Inês Pereira, de Gil Vicente);

B.o gênero textual solicitado em cada uma das propostas de produção escrita;

i.a presença de instruções relacionadas com todas as etapas da escrita: (i) a planificação; (ii) o registo; (iii) a revisão; (iv) a reescrita.

C.a clareza das orientações (explicitação dos passos do que era solicitado);

D.a perspectiva de escrita como função social ou apenas como tarefa escolar.

Quanto às notas de campo procedentes das observações de aula, procedeu-se à análise de conteúdo guiada pelas categorias e subcategorias seguintes:

A.o tipo de aula;

B.os recursos utilizados;

C.as orientações dadas pelos professores; 
D.a receptividade dos alunos;

E.o nível de interação entre os pares (aluno/aluno) e o nível de interação entre o professor e os alunos.

Na próxima secção, faremos a apresentação sucinta dos dados recolhidos, seguida da análise dos mesmos, para mostrarmos que resultado(s) o estudo permite extrair.

\section{APRESENTAÇÃO E DISCUSSÃO DOS RESULTADOS}

Neste trabalho não constam todos os dados produzidos nas observações das aulas, mas aqueles que se relacionam com as categorias de análise emersas ao longo do estudo como significativas no processo de pesquisa, com base na perspectiva teórica adotada.

\section{I Apresentação dos resultados}

Serão apresentados os resultados, em primeiro lugar, da análise dos materiais didáticos usados pelos professores e, em segundo lugar, da observação das aulas.

\section{I.I Materiais elaborados pelos professores}

As fichas de trabalho elaboradas pelos professores foram disponibilizadas aos alunos na primeira aula de ensino de escrita.

A ficha de $\mathrm{PI}$ (ver anexo I) continha um esquema com a estrutura do texto argumentativoexpositivo, com um tema prévio no cabeçalho. Este tema não se relacionava com o conteúdo em estudo (A Farsa de Inês Pereira, de Gil Vicente). A instrução continha uma indicação explícita sobre o gênero do texto a escrever (texto de opinião e texto de apreciação), mas sem referência a um possível contexto. Continha ainda a extensão definida em função do número de palavras (entre I50 e 200 palavras). Na instrução, não havia referência às etapas da escrita nem ao processo a seguir pelo aluno para produzir o texto. A atividade de escrita proposta pelo professor seguia o modelo apresentado no Exame Nacional, prova de avaliação externa de final do ensino secundário, que constitui prova obrigatória para quem quer prosseguir com os estudos no nível superior.

A ficha de trabalho de P2 (ver anexo 2) estava estruturada em função das etapas de escrita. Tal como nos mostra o item I, é sugerido ao aluno assistir a um documentário para depois (item I.2) estabelecer possíveis relações entre o assunto nele desenvolvido e o conteúdo das aulas anteriores. Em seguida, tendo em vista a escrita de um texto através do qual se dê a conhecer a situação atual das mulheres 
em vários dos países mencionados no documentário, o aluno é encaminhado (item 2) para a realização de uma pesquisa sobre o tema no país indicado pelo professor, mas que faz parte do documentário, com o propósito de levar o aluno a desenvolver várias estratégias de planificação de texto. $\bigcirc$ mesmo procedimento orientador relacionado com as etapas da textualização e da revisão textual constam também na ficha ((itens $2.1,3$ e 4).

As atividades de escrita propostas, tanto no material de PI quanto de P2, configuram o que Schneuwly e Dolz (1999, p. 8) classificam como um trabalho com gêneros sem "relação com uma situação de comunicação autêntica", mas voltado para a realização de uma tarefa escolar. Para uma melhor compreensão dos resultados, elencamos os pontos analisados no quadro seguinte:

Quadro 2 - Semelhanças e diferenças entre os materiais

\begin{tabular}{|c|c|c|}
\hline Categorias & PI & P2 \\
\hline $\begin{array}{c}\text { A. Relação do tema do texto com } \\
\text { o conteúdo em estudo }\end{array}$ & Não há relação. & $\begin{array}{c}\text { Há uma relação explicitada no material (o } \\
\text { tema, a situação das mulheres do } \\
\text { documentário exibido foi motivado pela } \\
\text { vida de Inês Pereira, personagem central } \\
\text { em A Farsa de Inês Pereira, de Gil Vicente }\end{array}$ \\
\hline $\begin{array}{c}\text { B. Indicação explícita do gênero } \\
\text { do texto a produzir }\end{array}$ & $\begin{array}{c}\text { Propõe a escrita do tipo expositivo- } \\
\text { argumentativo, no gênero apreciação } \\
\text { crítica e o texto de opinião, sem } \\
\text { determinar qual é o gênero. }\end{array}$ & $\begin{array}{c}\text { Propõe a escrita do texto expositivo, sem } \\
\text { determinar qual é o género. }\end{array}$ \\
\hline $\begin{array}{c}\text { C. Orientação processual da } \\
\text { atividade de escrita }\end{array}$ & $\begin{array}{c}\text { A proposta não contemplou as etapas } \\
\text { de planificação, revisão e reescrita. }\end{array}$ & $\begin{array}{c}\text { A proposta não contemplou a etapa de } \\
\text { reescrita. }\end{array}$ \\
\hline $\begin{array}{c}\text { D. Clareza das orientações } \\
\text { explicitação dos passos do que é } \\
\text { solicitado) }\end{array}$ & $\begin{array}{c}\text { A proposta foi sucinta, não } \\
\text { apresentando orientações sobre o que } \\
\text { era solicitado. }\end{array}$ & $\begin{array}{c}\text { A proposta apresentou orientaçes claras, } \\
\text { passo a passo, sobre o que era solicitado, } \\
\text { embora não determinasse qual o tipo } \\
\text { expositivo (argumentativo ou informativo) } \\
\text { e nem em qual gênero o texto deveria ser } \\
\text { escrito. }\end{array}$ \\
\hline $\begin{array}{c}\text { E. Perspectiva de escrita (função } \\
\text { social, tarefa escolar) }\end{array}$ & A escrita é proposta como tarefa \\
escolar. & A escrita é proposta como tarefa escolar. \\
\hline
\end{tabular}

Fonte: as autoras

\section{I.2 Notas de campo}

As notas de campo das aulas observadas permitem extrair um padrão assente em traços comuns a PI e a P2: a) ambos ministraram aula frontal; b) ambos interagiram com os alunos ao propor a escrita de um texto; c) ambos fizeram uso do quadro branco; d) ambos solicitaram que o texto fosse escrito em pares; e) nenhum deu qualquer orientação sobre como deveria ocorrer essa escrita a quatro mãos.

A fim de orientar a nossa análise das notas de campo recolhidas, estabelecemos as seguintes categorias:

I.estratégia e postura dos professores;

2.reflexão sobre a própria prática; 
3.definição da situação.

Relativamente à estratégia e postura dos professores, as notas de campo continham dados que permitem as descrições a seguir apresentadas.

- PI posicionou-se predominantemente à frente da turma e só ele tomou a palavra durante toda a aula; manteve um relacionamento cordial com todos, mas com um tratamento formal que estabelecia uma certa distância entre ele e os alunos; era bastante sério, falava baixo e pouco, determinava todas as ações dos alunos (quem lia, quem respondia às perguntas, quem seriam os pares); fez uso apenas do quadro branco, do manual escolar e de fichas de trabalho; não admitia nenhuma conversa paralela entre os alunos, mesmo que sobre o conteúdo em estudo.

P2 tinha uma postura extrovertida, falava mais alto que os alunos para impor um pouco de silêncio, dialogava bastante, mas também determinava várias ações dos alunos (como os lugares onde se sentavam e quem seriam os pares). Ao conduzir o debate sobre a relação entre a vida de Inês Pereira (personagem central de A Farsa de Inês Pereira, de Gil Vicente, a obra em estudo) e as mulheres que foram ouvidas no documentário Humans, ele manteve o controlo das interações dos alunos, mas com suavidade, permitindo que todos participassem e dando também a sua opinião sobre o tema em debate.

Sobre a reflexão sobre a própria prática, os dados registados foram sintetizados do modo que se segue. PI não fez nenhum comentário durante as aulas questionando a sua condução das mesmas. P2, durante a aula, aproximou-se da mesa da observadora e comentou "que o ideal teria sido levá-los para o laboratório de informática, mas tinha que agendar com antecedência e pela manhã está sempre ocupado". Também comentou, observando o silêncio, a concentração e a participação da turma e preocupado com o tempo que restava de aula, que demorou muito nas explicações, que "deveria ter ido direto para a ficha."

Quanto à definição da situação (impressões sobre um trabalho com a escrita), tanto PI como P2 disseram que normalmente não trabalham com a produção de textos em sala de aula, porque a atividade de escrita consome muito tempo da aula e eles têm de trabalhar todas as aprendizagens de um programa um pouco extenso. Na primeira reunião com PI, para acertarmos sobre as observações das aulas, ele comentou que não solicita a reescrita de textos aos alunos, pois não acredita que o aluno reescrevendo o mesmo texto irá aprender alguma coisa. Que ele prefere corrigir e mandar escrever um novo texto para ver o que o aluno aprendeu em relação ao texto anterior.

\subsection{Discussão e interpretação dos dados}

Com base nos dados apresentados, é possível pensarmos nos aspetos pedagógicos importantes que cada material nos revela. Assim, em PI, destacamos para reflexão o facto de a proposta de produção textual constituir uma tarefa escolar com um objetivo de aprendizagem definido como essencial nos 
documentos orientadores ("Escrever apreciações críticas, respeitando as marcas de género") mas sem apresentar qualquer relação com o conteúdo específico em estudo naquele momento (A Farsa de Inês Pereira, de Gil Vicente). De acordo com Antunes (2003), poderíamos afirmar que a atividade de escrita foi formulada como um ato isolado, em que se escreve sempre para a mesma pessoa. Para Geraldi ( 1997 ), esta prática reforça no aluno o papel de aluno-função e não de aluno-sujeito. À luz do quadro teórico em que se situa esse mesmo autor, este tipo de atividade, está fundamentada em determinados pressupostos que distancia-se muito da escrita com uma função social, a escrita em que o aluno tem o que dizer, tem uma razão para dizer o que diz e tem para quem dizer (prevendo um interlocutor diferente do professor), constituindo-se como sujeito do seu discurso e escolhendo estratégias para realizar os aspetos citados.

Em P2, o percurso proposto ao aluno sugere uma ligação entre a obra em estudo, que permite equacionar a representação da mulher pela perspetiva de Gil Vicente, e o mundo atual. Ao propor uma atividade de escrita sobre o papel da mulher na atualidade, em vários países, o professor coloca o aluno perante um problema a solucionar: pesquisar, documentar-se para depois expressar o seu ponto de vista. Parte-se, pois, do visionamento de um documentário, que não é um recurso naturalmente didático, mas que, uma vez trazido para a sala de aula, funciona como tal, cujo conteúdo se constitui objeto de comentário oral e até mesmo de debate, a partir do que foi solicitado nos itens I. I e 1.2 da ficha de trabalho. Além disso, como já foi referido, a ficha prevê uma preparação para a escrita (um caminho para a construção de conhecimentos prévios sobre o tema) através da pesquisa proposta e orientações específicas sobre a estruturação do texto e sobre a revisão do texto escrito, através de uma grelha. Tal como a atividade de $\mathrm{PI}$, a produção escrita dos alunos constitui também uma atividade circunscrita ao ambiente escolar.

Os resultados obtidos através da análise dos materiais elaborados pelos docentes e das aulas observadas mostram que os dois professores possuem diferentes perspectivas e concepções sobre ensino da escrita. Foi também visível que P2 se mostrou mais reflexivo sobre a sua prática de ensino, durante a aula.

Retomamos, então a questão de partida: existem diferenças no modo como o contexto e o processo de ensino-aprendizagem da expressão escrita são organizados por professores que frequentam formação e professores que não frequentam formação específica para o efeito? Os resultados preliminares do estudo exploratório em curso sugerem haver, de facto, diferenças substanciais, quer quanto à contextualização curricular da aprendizagem, quer quando à organização e gestão do processo durante a aula.

As diferenças destacadas pelos resultados apresentados parecem sugerir que, quanto mais temporalmente afastados de uma experiência de formação em didática da escrita, menor a intensidade de um trabalho sistemático de produção de texto com os alunos. No caso concreto dos procedimentos 
habituais de um professor em aula de produção textual, quando afastado de experiências de formação, este tende a atuar de acordo com o referido por Antunes (2003): os professores, por diversas razões, não desenvolvem um trabalho sistemático de produção textual; quando o fazem não desenvolvem todas as etapas da escrita assinaladas por Flower \& Hayes ( 198 I), ou seja, a planificação, a textualização e a revisão; quando há a revisão dos textos, os professores centram-se numa correção do tipo indicativa e classificatória (SERAFINI, 1989), que, segundo Ruiz (2005), não contribui para o entendimento do aluno sobre o problema que o texto apresenta, oportunizando a reescrita, caso viessem a reescrever, e, ainda, não solicitam a reescrita dos textos aos alunos.

Esta ilação necessita, contudo, de estudos que investiguem de modo mais aprofundado esta questão: após uma experiência de formação, a partir de que momento é que começam a deixar de se fazer sentir os seus efeitos na prática letiva diária?

\section{CONSIDERAÇÕES FINAIS}

Com este estudo não pretendemos emitir quaisquer juízos de valor sobre as práticas letivas e os materiais didáticos em referência, dado não haver qualquer propósito normativo na investigação-ação realizada. O propósito foi analisar, como referido na introdução, os materiais citados, identificar os gestos profissionais dos professores em momentos de ensino de produção escrita em aula e refletir sobre a influência da formação contínua nos materiais e nos gestos profissionais identificados.

Os resultados autorizam algumas considerações necessárias para a consecução do trabalho de formação de professores em curso.

Em primeiro lugar, verificou-se que existiu um efeito positivo significativo nas aulas observadas do trabalho oficinal realizado nas sessões de formação por P2 com os seus pares. Apesar de poder ser apontada como limitação a observação de um único professor, no conjunto dos 21 docentes que realizaram a formação, sendo admissível considerar outras variáveis imputáveis a esse efeito (como a formação acadêmica e formação inicial deste professor, entre outras), não se pode excluir essa influência. Convém, contudo, ter em mente que o efeito positivo foi verificado em aulas realizadas no período de realização da formação. Será necessário estudar esse efeito em momentos progressivamente mais distantes da conclusão da formação.

Em segundo lugar, registou-se que, tendo sido cada um dos professores participantes neste estudo a decidir o agendamento das aulas a serem observadas e a planificação dessas aulas, assumiram maior predominância as atividades de planificação e de textualização, tendo os procedimentos de revisão e de reescrita de textos ficado num plano secundário. Com efeito, ainda que a referência à necessidade de rever o texto depois de os alunos o escreverem tenha estado presente, nos materiais e no discurso oral 
dos professores, na verdade não foi realizado pelos alunos um trabalho oficinal de reescrita em função de um feedback circunstanciado. Houve, portanto, um investimento menor em procedimentos de revisão e reescrita do texto, resultante da grande concentração de atenção em atividades de planificação de texto. Embora seja inquestionável a importância das estratégias de planificação de texto, investigações recentes demonstram que as grandes aprendizagens dos alunos decorrem do feedback do professor geradores da revisão e aperfeiçoamento de texto (RUIZ, 2005; FUZER, 2012, entre outros). Este resultado tornou mais evidente uma das limitações da oficina de formação realizada: será necessário um investimento maior na reflexão conjunta de professores sobre as suas práticas de ensino da escrita com ênfase na revisão e reescrita dos textos pelos alunos em sala de aula.

Em terceiro lugar, constatou-se uma prevalência dos enfoques processual e compositivo do ensino da escrita. Outros enfoques do ensino da escrita, como, por exemplo, o comunicativo, que dá relevo à escrita social, poderia ser integrado nas sequências de aprendizagem de modo a otimizar a competência de escrita dos alunos. Geraldi (1997, p. 137), por exemplo, estabelece uma distinção entre 'produção textual' e 'redação', destacando que, na primeira, os textos são produzidos na escola e, na segunda, para a escola. Nesta última perspectiva, como já dito, as solicitações dos professores não levam em conta que para escrever é preciso que

a) se tenha o que dizer; b) se tenha uma razão para dizer o que se tem a dizer; c) se tenha para quem dizer o que se tem a dizer; d) o locutor se constitua como tal, enquanto sujeito que diz o que diz para quem diz (...) e se escolham as estratégias para realizar a), b), c), e d).

Para ele, dessa forma, a escola produz muita escrita e pouco texto/discurso7. Sendo assim, a escrita produzida pelos alunos (redações) é realizada para responder a uma instrução do professor (tarefa escolar) e não tem uma função social fora do circuito escolar. $\bigcirc$ aluno não produz o seu discurso nesta escrita, responsabilizando-se pelo que pensa, mas produz uma escrita que sabe que vai ao encontro das expectativas do professor sobre o que foi solicitado. Nesse sentido, para o autor, como já dito, o sujeitoaluno dá lugar à função-aluno. Importa lembrar que Geraldi ( 1997) considera a produção de textos escritos (e também orais) como o ponto de partida e de chegada para o processo de ensino-aprendizagem da língua, porque possibilita que o sujeito-aluno tenha voz, produza o seu discurso. A escola tem uma grande responsabilidade social de formar escritores para a vida, com uma escrita voltada para fora dos seus muros. Bazerman (20I4, p. 27) destaca essa dimensão, quando afirma que:

Escribir fuera de la escuela significa comprometerse con redes sociales complejas, conocimientos, evidencias e ideas. Se trata de decisiones y adopción de medidas sobre la base del conocimiento

\footnotetext{
7 Juntamente com Lopes e Carapinha (2013), «Partiremos (...) da opinião de todos aqueles que adotam uma visão integradora dos dois termos, concebendo as expressões 'texto' e 'discurso' como sinónimos (FONSECA, 1992, p. 105) e subsumindo sob essa designação qualquer segmento linguístico de extensão variável, dotado de unidade semântica e relevância pragmática, produzido intencionalmente por um locutor, numa situação concreta, e visando obter um efeito comunicativo sobre um determinado locutor» (p. 12).
} 
y el pensamiento. Se trata de ser escuchado y a quien se le presta atención. Se requiere coraje para afirmar la propia voz y se necesita confianza para superar las incertidumbres y ansiedades. Pero en cada dominio del conocimiento pertinente, ser capaz de representar ese conocimiento relevantemente y organizar ese conocimiento y razonar sobre lo que es apropiado a ese dominio en relación con los intereses propios, la situación y las necesidades e intereses de otros le da a uno la confianza de afirmar su voz, para llamar la atención sobre lo que se tiene que decir.

O estudo preliminar agora apresentado será completado com uma análise de entrevistas a realizar a estes professores para se compreender melhor as suas concepções de escrita e de ensino da escrita, bem como os fundamentos das atividades letivas realizadas com os alunos. É importante conhecer melhor cada um dos professores para além dos dados recolhidos, como as idades, a formação acadêmica e a formação inicial, o percurso profissional, as experiências como sujeitos-escreventes, entre outros aspetos.

Sabemos que qualquer caminho para uma mudança é longo e requer muito trabalho. O tempo de mudança para as transformações que um trabalho com a escrita na escola requer é um tempo histórico. Hoje, em pleno século $X X \mid$, estamos rodeados de novas formas de escrever (em suportes digitais, por exemplo) que ainda em muitas salas de aula não estão presentes. Mas sabemos também que essa transformação ocorre dentro do professor, a partir da sua própria reflexão sobre e com as experiências letivas. Nesse sentido, a formação contínua é essencial como dispositivo acelerador dessa reflexão, com base em configurações diferentes de desenvolvimento de profissionais reflexivos.

\section{REFERÊNCIAS}

ADAM, J-M. A linguística: introdução à análise textual dos discursos. São Paulo: Cortez, 2008.

AMOR, E. Didáctica do Português: Fundamentos e metodologia. Lisboa: Texto Editora, 1993.

ANTUNES, I. Aulas de Português: encontro \& interação. São Paulo: Parábola Editorial. 2003.

BAZERMAN, C. La escritura en el mundo del conocimiento: al encuentro de nuestra voz en la escuela, la universidad, la profesión y la sociedad. Verbum, Bogotá, 9(9), 23-35, 2014.

BOGDAN, R.; BIKLEN, S. Investigação Qualitativa em Educação: uma introdução à teoria e aos métodos. Porto: Porto Editora, 1994.

BEAUGRANDE, R. de; DRESSLER, W. Introduction to Textlinguistics. London: Longman, I98I.

CAMPS, A. Modelos del proceso de redacción: algunas implicaciones para la enseñanza. Infancia y Aprendizaje, Madrid, 49, 3-19, 1990.

CAMPS, A. L'ensenyament de la composició escrita. Barcelona: Barcanova, 1994.

CAMPS, A. (Coord.) Secuencias didácticas para aprender a escribir. Barcelona: Graó, 2003.

CASSANY, D. Describir el escribir: cómo se aprende a escribir. Buenos Aires: Editorial Paidós, 1989. 
CASSANY, D. Enfoques didácticos para la enseñanza de la expresión escrita. Comunicación, Lenguaje y Educación, Madrid, 6, 63-80, 1990.

CASSANY, D. La cocina de la escritura. Barcelona: Editorial Anagrama, 1995.

COUTINHO, M. A. Macroestruturas e microestruturas textuais. In DUARTE, I. M.; FIGUEIREDO, O. (Orgs), Português, língua e ensino, Porto: U. Porto Editorial, 201 I, p. 191-222.

DOLZ, J.; NOVERRAZ, M.; SCHNEUWLY, B. Sequências didáticas para o oral e a escrita: apresentação de um procedimento. In Schneuwly, B.; Dolz, J. (Orgs.). Gêneros orais e escritos na escola. Campinas: Mercado de Letras, 2004.

ESTRELA, A. Teoria e prática de observação de classes. Porto: Porto Editora, 1990.

FLOWER, L. \& HAYES, J. A cognitive process theory of writing. College Composition and Communication. Urbana, Illinois, 32 (4): pp. 365-387, Dec. 1981.

FUZER, C. Bilhete orientador como instrumento de interação no processo ensino-aprendizagem de produção textual. Revista Letras, Santa Maria, Vol. 22, n. 44, p. 213-245, jan/jun, 2012.

GERALDI, J. W. Portos de Passagem. São Paulo: Martins Fontes, 1997.

JOLIBERT, J. (coord.). Former des Enfants Producteurs de Textes. Paris: Hachette-Écoles, 1988.

JOLIBERT, J. ; SRAÏKI, C. Des enfants lecteurs et producteurs de textes. Cycles 2 et 3. Paris: Hachette Éducation, 2006.

JORGE, N. e COUTINHO, A. Percursos (linguísticos) de leitura (literária). Palavras. Revista da Associação de Professores de Português, Lisboa, n. 50-5I, p. 77-87, outono 2016-primavera 2017.

JORGE. N. "A exposição oral no $5 .^{\circ}$ ano de escolaridade: relato de percurso didático". In Atas do $13 .^{\circ}$ ENAPP - Percursos da interdisciplinaridade em Português: 13. ${ }^{\circ}$ ENAPP. Lisboa: APP, 2019, p. 59-70.

KEMMIS, S.; McTAGGART, R. (eds.). The action research planner. Victoria: Deakin University Press, 1988.

LOPES, A. C. M.; CARAPINHA, C. Texto, coesão e coerência. Coimbra: Almedina-CELGA, 2013.

MARCUSCHI, L. A. Da fala para a escrita: atividades de retextualização. São Paulo: Cortez, 20 I0.

MATEUS, M. H. M. et al. Gramática da Língua Portuguesa. Lisboa: Editorial Caminho, 2003.

NÓVOA, A. Formação de professores e profissão docente (coord.). In Os professores e a sua formação. Lisboa: Dom Quixote, 1992.

NÓVOA, A. Formação de Professores e Trabalho Pedagógico. Lisboa: Educa, 2002.

NOVOA, A. Firmar a posição como professor, afirmar a profissão docente. Cadernos de Pesquisa, vol.47, n. I66, p. II06-1 I33, 2017. 
PEREIRA, L. A.; ALEIXO, C.; CARDOSO, I. e GRAÇA, L. The teaching and learning of writing in Portugal: The case of a research group. In BAZERMAN, C.; KRUT, R.; LUNSFORD, K.; MCLEOD, S.; NULL, S.; ROGERS, P. M.; STANSELL, A. (Eds.), Traditions of Writing Research. Oxford: Routledge, 2010, p. 58-70.

PEREIRA, L. Á; CARDOSO, I.; GRAÇA, L. Para a definição da sequência de ensino como dispositivo para a aprendizagem da escrita: enquadramento teórico e exemplos da prática. In RIESTRA, D.; TAPIA, S. M.; e GOICOECHEA, M. V. (Orgs). Terceras Jornadas Internacionales de Investigación y Prácticas en Didáctica de las lenguas y las literaturas, Bariloche: Ediciones GEISE, 20 I3, p. 293-3 16.

PINTO, M. G. L. C. A escrita: um processo recursivo movido pela revisão? In PINTO, M. G. L. C. A escrita: o papel da universidade na sua otimização. Porto: Faculdade de Letras da Universidade do Porto, 20|4, p. |9|-22|.

PORTUGAL, Ministério da Educação/Direção-Geral da Educação. Aprendizagens Essenciais. Lisboa: ME/DGE, 2018.

RUIZ, E. Como se corrige redação na escola. São Paulo: Contexto, 2005.

SANTOS, $\mathrm{O}$. Um modelo de estratégia de ensino-aprendizagem da escrita na aula de língua materna. In FONSECA, F. I. (Org.), Pedagogia da escrita: perspetivas. Porto: Porto Editora, I 994, p. I27- I 53.

SCHNEUWLY, B. e DOLZ, J. Os gêneros escolares: das práticas de linguagem aos objetos de ensino, São Paulo, Revista Brasileira de Educação, no. 1 I , p.05-16, Ago 1999.

SERAFINI, M. T. Como escrever textos. Tradução de Maria Augusta Bastos de Mattos. São Paulo: Globo, 1989.

TARDIF, M. Saberes Docentes \& Formação Profissional. I I ed. Petrópolis, RJ: Vozes, 2010.

UNESCO-IBE. Glossário de Terminologia Curricular. Versão em português coordenada pelo Setor de Educação da Representação da UNESCO no Brasil, 2016. Disponível em https://unesdoc.unesco.org/ark:/48223/pf0000223059_por?posInSet=12\&queryld=3. Acesso em 28/04/2020. 


\section{ANEXO I - MATERIAL DIDÁTICO DE PI}

Texto de Apreciação crítica: Livro

Texto de Apreciação Crítica e Texto de Opinião/Texto expositivo-argumentativo

\begin{tabular}{|l|l|l|}
\hline Grupo - & Título & \\
\hline & $1 .{ }^{\circ} \S$ Apresentação da tese & \\
\hline & $2 .{ }^{\circ} \S$ Argumento e exemplo & \\
\hline & 3 ○ Argumento e exemplo & \\
\hline & $\begin{array}{l}4 .{ }^{\circ} \S \text { Conclusão } \\
\text { (Texto circular) }\end{array}$ & \\
\hline
\end{tabular}

Autoria:

Foi proposto o tipo textual expositivo-argumentativo, no género apreciação crítica, que deveria ser feita sobre livros ou filmes, a escolha dos alunos. Além disso, havia a proposta de escreverem textos de opinião, mas sem determinar exatamente qual é o gênero. Para esta última, o professor propôs três temas distintos: I. A música como a arte preferida dos jovens; 2. Os jovens e o álcool e 3. A vida escolar e a Escola Tal. 


\section{ANEXO 2 - MATERIAL DIDÁTICO DE P2}

Português I 10. Ano Ensino Profissional

Escrita: Texto Expositivo

Duração da atividade: 4 tempos letivos

I. Assiste ao excerto do documentário Humans, da autoria de Yann Arthus-Bertrand, integrado num projeto da Fundação Good Planet.

I. I. Das situações relatadas pelas intervenientes neste documentário, indica as que mais te impressionaram.

I. 2. No documentário são retratadas sociedades do séc. XXI. Consegues estabelecer alguns pontos de contacto entre a vida destas mulheres e a vida de Inês

Pereira, no séc. XVI? Indica-os.

2. Elabora, agora, uma pesquisa sobre o papel da mulher, no século $X X \mathrm{X}$, em diferentes partes do mundo. Para tal, sair-te-á em sorte um dos seguintes países: Itália, Senegal, Cazaquistão, Líbia, Peru, Burquina Faso, México, Brasil, Índia e Ruanda.

2. I. Com os dados recolhidos, preenche a tabela seguinte.

\begin{tabular}{|l|l|}
\hline $\begin{array}{l}\text { Introdução } \\
\text { (apresentação do tema) }\end{array}$ \\
\hline $\begin{array}{l}\text { Desenvolvimento } \\
\text { (apresentação de informação factual e respetivos }\end{array}$ & $\begin{array}{l}\text { - Acesso à escola: } \\
\text { exemplos) }\end{array}$ \\
& $\begin{array}{l}\text { - Comportamento mocial que se espera que a mulher adote: } \\
\text { - Vida profissional: }\end{array}$ \\
\hline $\begin{array}{l}\text { Conclusão } \\
\text { (síntese da informação anterior) }\end{array}$ & \\
\hline
\end{tabular}

3. A partir da tabela que preencheste, elabora um texto expositivo, subordinado ao tema "O papel da mulher na sociedade do século XXI - o caso do (nome do país selecionado)", respeitando as seguintes orientações:

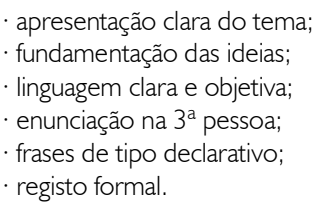

4. Por último, revê o teu texto, preenchendo a tabela de autoavaliação.

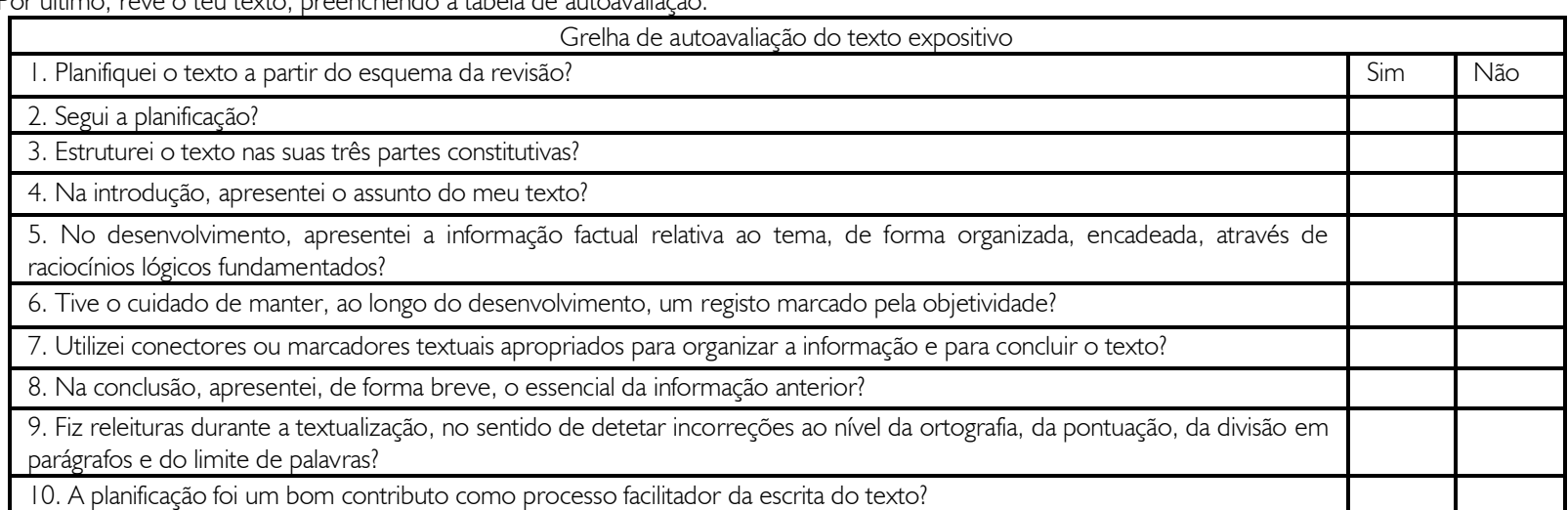

Todos os anos, a 8 de março, a comunidade internacional celebra o Dia Internacional da Mulher. É uma ocasião para dar um enfoque particular, em todo o mundo, á luta pela igualdade entre homens e mulheres e para lançar iniciativas de sensibilização que contribuam para uma mudança de mentalidades. A promoção da igualdade de género assume um grau de prioridade na UNESCO. Em todos os domínios do seu mandato - educação, cultura, ciência, comunicação e Informação - a UNESCO está empenhada em incentivar o acesso das raparigas e mulheres a todos os setores de educação e formação, eliminando as barreiras que impedem o seu desenvolvimento pessoal e proflsslonal, permitindo-Ihes uma maior representação na vida cultural, científica e dos media.

Mensagem da Diretora-geral da UNESCO, Audrey Azoulay, por ocasião da comemoração do Dia Internacional da Mulher 


\section{COMO CITAR ESSE ARTIGO}

\section{Associação Brasileira de Normas Técnicas (ABNT)}

PIMENTA, Rosângela Oliveira Cruz; RODRIGUES, Sónia Valente. Formação contínua de professores portugueses no contexto do ensino-aprendizagem da expressão escrita: estudo preliminar. Debates em Educação, Maceió, v. I2, p. 220-245, set. 2020. ISSN 2 175-6600. Disponível em:

https://www.seer.ufal.br/index.php/debateseducacao/article/view/I0I I5. Acesso em: dd mmm. aaaa.

\section{American Psychological Association (APA)}

Pimenta, R., \& Rodrigues, S. (2020). Formação contínua de professores portugueses no contexto do ensino-aprendizagem da expressão escrita: estudo preliminar. Debates em Educação, 12 (Esp), 220245. doi: https://doi.org/10.28998/2175-6600.2020v I2nEspp220-245 